\title{
A IMPORTÂNCIA DOS EQUIPAMENTOS DE SEGURANÇA CONTRA INCÊNDIO NAS EMPRESAS
}

\author{
Carlos Rychlewski Gomes
}

Universidade do Oeste Paulista - UNOESTE, Faculdade de Engenharia, pós-graduação lato sensu (especialização) em Engenharia de Segurança do Trabalho, orientador: Eng. Ms. Ivam Liboni.

\section{RESUMO}

Este artigo teve o objetivo de investigar a importância dos equipamentos de segurança nas empresas, enfocando os equipamentos contra incêndio. Para isso, fez uma pesquisa bibliográfica sobre o tema proposto, pesquisando em livros, revistas científicas, artigos científicos e sites de Internet. Quanto a importância dos extintores de incêndio para as empresas, ficou nítido que esta proteção coletiva dentro dos ambientes empresariais fará com que a segurança aumente. Entretanto, é necessário oferecer treinamento para o seu uso correto. Outro ponto a ser observado é que os extintores devem estar carregados e conferidos, para que estejam adequados quando houver necessidade de seu uso. É necessário contratar empresas particulares de recarga de extintor de incêndio que realizam serviços e funções muito peculiares, já que, além de necessitarem de registro adequado, também lidam com a vida e morte de pessoas, pois um serviço mal feito ou com matéria prima em condições precárias pode levar alguém a morte. Reforça-se que as empresas devem ter um controle grande quanto ao serviço prestado, pois a responsabilidade civil dos funcionários sobre um serviço mal feito também é verificada, já que estes acabam praticando ato doloso ou culposo, na realização das tarefas relativas à temática abordada.

Palavras-chave: segurança; empresa; extintor de incêndio.

\section{THE IMPORTANCE OF FIRE SAFETY EQUIPMENT ON BUSINESS}

\section{ABSTRACT}

This project aimed to investigate the importance of safety equipment in enterprises, focusing on fire fighting equipment. To do this, did a literature search about the theme, reading books, journals, news papers and Internet sites. As the importance of fire extinguishers for businesses, it became clear that this collective protection in business environments that will increase safety. However, it is necessary to provide training for its correct use. Another point to note is that fire extinguishers should be loaded and verified, so they are appropriate when there is a need for its use. It is necessary to hire private contractors to recharge fire extinguisher that perform services and functions very peculiar, since, in addition to requiring proper registration, also dealing with life and death of people, for a service done poorly or with raw materials at poor can lead someone to death. It is stressed that companies must have a strong control on the service, because the liability of employees on a sloppy service is also verified, since they end up practicing willful or grossly negligent act, in carrying out tasks related to the theme.

Keywords: security; company; fire extinguisher. 


\section{INTRODUÇÃO}

O fogo é conhecido desde a pré-história e sempre trouxe muitos benefícios para o homem. Entretanto, quando este passa a fugir do controle do homem, se torna um problema, passando a se chamar incêndio. Com isso, foram sendo inventados novos negócios de forma a obter materiais que pudessem controlar o incêndio, assim como treinamentos para utilizar os mesmos.

Os bombeiros são os profissionais especializados neste tipo de situação, isto é, controlar incêndios. Entretanto, qualquer pessoa, em sua residência, automóvel ou empresa, passou a poder se defender de pequenos incêndios com a invenção dos extintores de incêndio, que são aparelhos portáteis que servem para extinguir princípios de incêndio.

De acordo com o Art. 162 da Consolidação das Leis do Trabalho (CLT), atualizada pela Portaria 01/95 do Ministério do Trabalho, foram estruturados os Serviços Especializados em Engenharia de Segurança e Medicina do Trabalho - SESMT, de presença obrigatória nas empresas com mais de 100 trabalhadores. Ainda, o Programa de Prevenção de Riscos Ambientais (PPRA), o Programa de Controle Médico de Saúde Ocupacional (PCMSO), a Comissão Interna de Prevenção de Acidentes (CIPA) e demais Normas Regulamentadoras (NR) do assunto, passaram a integrar a pauta dos serviços de responsabilidade do segmento de segurança do trabalho.

Modernamente, a gestão de segurança do trabalho engloba em seus eixos de atuação as condições do local de trabalho, a qualidade do mesmo e a forma de atuação do funcionário, passando essas a representarem competências essenciais vinculadas ao próprio modelo de gerenciamento de segurança.
A organização, condições e relações de trabalho compõem, na verdade, o contexto organizacional. As avaliações circunstanciais do ambiente funcionam como um termômetro que indica a segurança da empresa. A ergonomia e a própria psicodinâmica do trabalho, aliadas às medidas quantitativas e qualitativas, contribuem na construção de um local atento às questões de segurança ocupacional.

Assim, este trabalho tem o objetivo de investigar a importância dos equipamentos de segurança nas empresas, enfocando os equipamentos contra incêndio.

Para isso, faz uma pesquisa bibliográfica sobre o tema proposto, pesquisando em livros, revistas científicas, artigos científicos e sites de Internet.

\section{MATERIAIS E MÉTODOS}

O método utilizado para este artigo foi o dedutivo. Foi feita uma pesquisa bibliográfica, fazendo uma revisão em livros, artigos científicos e revistas especializadas, além de leis e normas regulamentadoras.

\section{DESENVOLVIMENTO}

\subsection{SEGURANÇA DO TRABALHO}

A própria evolução da sociedade a partir de decisões administrativas e técnicas introduzidas por projetos e programas nas áreas de educação, previdência, saúde e do trabalho trouxeram consequências diversas como, crise econômica, desemprego, racionalização do trabalho, necessidade de qualificação da força de trabalho, que acabaram por favorecer e estimular os agravos provocados pelo trabalho, como os acidentes e as doenças. (SALEM; SALEM, 2005).

No ambiente de trabalho, existem riscos nas diversas formas de cargas, que podem interferir na saúde do trabalhador. As condições 
de trabalho não são estáticas, pois sofrem transformações sob a influência da evolução das forças produtivas. Entende-se por forças produtivas a técnica, a organização do trabalho e a força de trabalho humana. "As mudanças ocorridas nas forças produtivas dos países industrializados, por volta da década de 70 do século XX, caracterizaram o desejo de "cientificar" os ambientes funcionais" (SALEM; SALEM, 2005, p. 23).

Desse modo, é válido considerar que os agravos à saúde do trabalhador podem decorrer da aplicação de novas técnicas introduzidas no processo de trabalho. Portanto, é válido entender que as características inerentes ao desenvolvimento da estrutura econômica e da evolução tecnológica são transportadas na forma de riscos para o cotidiano do trabalhador.

Nessa linha, importa reconhecer 0 interesse sobre 0 assunto demonstrado por segmentos diversos de estudos, destacando-se os profissionais de medicina e segurança do trabalho e, de um modo geral, os administradores, que modernamente respondem por gestões estratégicas.

Assim, é exatamente a partir dessa conjuntura de fatos que são ressaltadas as medidas e procedimentos voltados à segurança do trabalho. Estes priorizam a prevenção de acidentes, a eliminação de riscos a doenças ocupacionais, como também à adequação do trabalhador ao seu posto funcional.

No que se refere aos fatores passíveis de predisposição ao risco é importante ressaltar que estes se relacionam tanto à pessoa como à empresa. No primeiro caso, pode-se levar em conta a falta de conhecimento do processo de trabalho, o não cumprimento de normas e regras de segurança, as atitudes e comportamentos inadequados, a exposição desnecessária a situações de riscos e, ainda, o uso inadequado dos equipamentos.
Já em relação à empresa, são responsabilidades por fontes de riscos: ausência de manutenções e, por conseqüência, falhas de maquinários e equipamentos, instalações sem recursos de segurança e sem garantia de bemestar à execução dos serviços, como por exemplo, iluminação precária. Na realidade, além destes itens, inúmeros outros podem ser considerados como ameaças ao desempenho seguro das atividades laborais. (CARAVANTES et al., 1997).

Procurando minimizar a questão, muitas empresas criaram ou estão criando programas eficientes de segurança com redução, de forma acentuada, nas taxas de acidentes de trabalho e das doenças profissionais, inclusive com a divulgação diária para os públicos interno e externo dos respectivos resultados.

Nessa linha, em conformidade com os estudos de Tavares (2003), importa ainda considerar que as providências atualmente adotadas na construção de um ambiente de trabalho seguro devem contribuir para a qualidade de vida do trabalhador.

\subsection{DISPOSITIVOS LEGAIS DA SEGURANÇA DO TRABALHO}

Para compreensão das bases legais que regem o assunto é importante iniciar com os comentários de Dias (1996, p. 73):

No cenário empresarial brasileiro, a saúde do trabalhador passa pelas diretrizes privadas e públicas, tendo como responsáveis tanto os empregadores, como o governo. Ocorre que na prática é preciso defender a manutenção e permanente melhoria de qualidade de vida do trabalhador, sobretudo em relação a sua segurança no ambiente de trabalho.

Nessa linha, as Normas Regulamentadoras do Ministério do Trabalho, hoje em vigor, ditam as bases da maioria dos 
projetos e programas de Saúde e Segurança do Trabalho.

A Constituição Federal (CF), promulgada em 1988, pode ser considerada como o alicerce para os parâmetros legais voltados à segurança dos trabalhadores (BRASIL, CF/88).

Além disso, o contexto de segurança do trabalho também vem sendo objeto de discussão pelos sindicatos e órgãos representativos de classes profissionais. Assim, cláusulas específicas têm sido encontradas em Acordos e Convenções Coletivas de categorias de trabalho que, cada vez mais, adentram nos assuntos de segurança e saúde do trabalhador. Como verdadeiros instrumentos de regulação estes Acordos definem condições de segurança nos ambientes organizacionais.

Vale ainda acrescentar a informação de Saliba (2005) em relação ao negociado pelos trabalhadores durante o Fórum Nacional sobre Segurança e Saúde do Trabalhador no Contrato Coletivo de Trabalho, realizado no Distrito Federal em 1994. No evento foi abordada a tendência, através das categorias de trabalho mais organizadas, à substituição das vantagens instituídas em normas genéricas da legislação relativas a medidas de segurança, pelas definidas em instrumentos de categorias: Acordos e Convenções (SALIBA, 2005).

Assim, a normalização das responsabilidades por essa segurança forma um conjunto de Normas Regulamentadoras. $\mathrm{Na}$ realidade, a Consolidação das Leis do Trabalho (CLT), com a 1a edição em 1943, já determinava vários procedimentos acerca da saúde no trabalho. (CLT, 2004).

A Portaria 3.237/72 do MTb regulamentou os Serviços Especializados em Engenharia de Segurança e Medicina do Trabalho (SESMT), que passaram a ser obrigatórios conforme o grau de risco da atividade de cada empresa, bem como de acordo com o total de funcionários. Essa medida foi adotada na época em virtude do grande número de acidentes no trabalho. (BRASIL, 1972).

Já as Normas Regulamentadoras (NR) instituídas pela Portaria 3.214/78 (BRASIL, 1978) estão sendo continuamente atualizadas e complementam o Capítulo V da CLT fornecendo diretrizes básicas para a inspeção e fiscalização dos ambientes e condições de trabalho, a partir dos deveres das empresas. Inclusive, hoje em dia, os SESMTs são regidos pela Norma Regulamentadora $n^{\circ}$ 4, que já foi reformulada em 1983, que trata especificamente dos Serviços Especializados em Engenharia de Segurança e Medicina do Trabalho.

\subsubsection{Normas regulamentadoras}

No que se refere ao cotidiano do serviço de segurança do trabalho, destaca-se:

NR 5: Comissão Interna de Prevenção de Acidentes (CIPA)

Com o intuito fundamental de prevenir acidentes de trabalho, foi criada uma comissão: Comissão Interna de Prevenção de Acidentes (CIPA). Esta é composta de representantes da empresa e representantes dos empregados da empresa, os quais ficam em mandato por um ano e é obrigatória para as empresas que possuam empregados com vínculo empregatício.

A NR que trata da CIPA foi publicada em 1999 com a Portaria no 08 e sua última atualização foi realizada em 2001 por meio da Portaria $n^{0}$ 16. $E$ as disposições contidas no respectivo documento aplicam-se aos trabalhadores avulsos e às organizações contratantes de serviços de terceiros. Araújo (2005, p. 13) acrescenta que:

Em relação a empresa que possuir em um mesmo município dois ou mais estabelecimentos, deverá garantir a integração das CIPA e dos designados, conforme o caso, com o 
objetivo de harmonizar as políticas de segurança e saúde no trabalho.

A CIPA tem como principal objetivo "a prevenção de acidentes e doenças decorrentes do trabalho, de modo a tornar compatível permanentemente o trabalho com a preservação da vida e a promoção da saúde do trabalhador". (NR 5).

De acordo com Araújo (2005, p. 23):

\begin{abstract}
O plano de ação desta comissão é o de elaborar ações preventivas na solução de problemas de segurança e saúde do trabalhador, identificando os riscos do processo de trabalho com a participação do maior número de trabalhadores. Essa identificação dos riscos tem que ser periódica e, as informações reativas à segurança, precisam ser constantemente transmitidas.
\end{abstract}

Nesta Norma também é definida a elaboração do Mapa de Riscos. Trata-se de um documento que representa graficamente os riscos sobre o layout do local de trabalho analisado. Indica através de círculos: grupo de risco de acordo com a cor padronizada; número de trabalhadores expostos ao risco; identidade do risco de acordo com a gravidade. (ANVISA, 2010).

Portanto, constitui-se em um documento que demonstra expressamente os riscos do ambiente de trabalho, sinalizando-os sobre a planta do local. Segue normas específicas com a indicação por círculos de cor variada para caracterizar o grupo de risco a que se refere.

NR-6 - Equipamento de Proteção Individual - EPI - da Portaria MTb nº 3.214/78

Os Equipamentos de Proteção definidos pela NR 6 são ferramentas e instrumentos de trabalho que objetivam assegurar a proteção à saúde do homem, reduzindo os riscos iminentes, previstos ou não.
São várias as vias de exposição ao risco e, portanto, existem classes específicas de equipamentos para a prevenção de acidentes e contaminações, ou impactos à integridade física do homem.

No contexto empresarial, os equipamentos de proteção estão relacionados à ergonomia de postos de trabalho, como também as questões ligadas à insalubridade e /ou periculosidade.

Equipamentos de Proteção Coletivos (EPC)

De forma semelhante ao EPI, o EPC tem por objetivo principal a proteção coletiva de organismos em relação a acidentes ou riscos à doença.

Também está enquadrado nas exigências legais e deve ser construído e fabricado de acordo com especificações técnicas pertinentes.

Em empresas, sua função principal é a de reduzir doenças (profissionais ou não), como também prevenir riscos de acidentes. Existem muitos equipamentos de proteção coletivos mas será especificado o extintor de incêndio, que, de acordo com os dados constantes do Globaltech (2006), é um dos equipamentos mais comuns e mais utilizados pelas empresas:

Extintor de incêndio e demais ferramentas contra incêndio, como também a construção de escadas externas. 


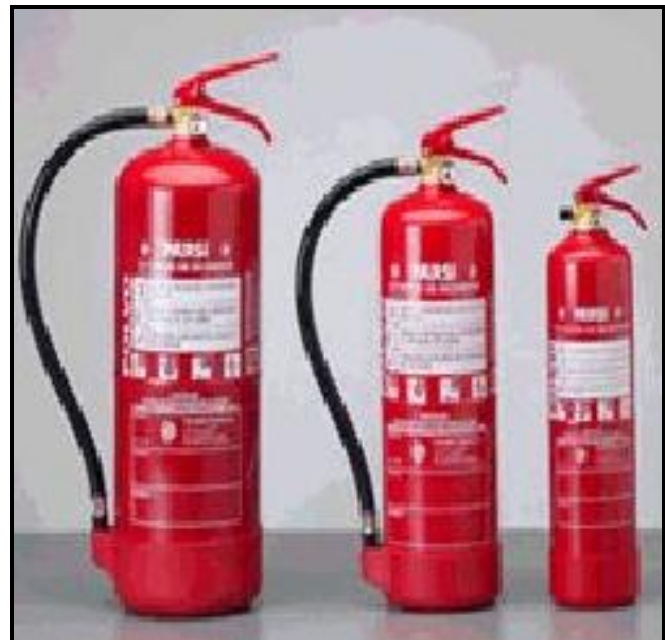

FIGURA 1 - Extintor de Incêndio

Fonte: Danny.com, 2010

As construções para proteção contra incêndio têm que considerar as condições locais, instalações e demais fatores presentes na construção e disposição dos objetos e mobiliários.

Quanto aos extintores, estes obedecem ao tipo de risco iminente devendo ser projetado de acordo com as atividades locais. São os mais usados:

- Espuma mecânica;

- Jatos de água na forma líquida;

- Gases e vapores inertes (CO2, N, Vapor de água);

- Pó químico;

- Agentes halogenados

Este tipo de aparelho deve estar em local visível e de fácil acesso, devendo haver treinamento para seu uso correto. Eles somente funcionam se alguém os manusear de forma correta e levar os mesmos até o local do incêndio, apontando corretamente para o foco e ativa-lo de forma a extinguir as chamas.

Todo edifício, condomínio, ponto comercial e industrial e até mesmo automóveis, caminhões e ônibus devem contar com extintores de incêndio. Assim, devem estar funcionamento perfeitamente para que possam ser eficientes.
Para a recarga dos extintores de incêndio existem empresas especializadas, onde deve haver uma equipe de trabalho responsável, que conte com bons fornecedores de produtos químicos e saiba lidar com os equipamentos de forma segura. A recarga dos extintores são muito importante pois o funcionamento perfeito destes equipamentos vai influenciar na vida ou morte daquele que necessite dele.

Em caso de falhas na manutenção dos extintores, pode haver a responsabilidade civil e até mesmo criminal das empresas responsáveis por este serviço.

Por causa disso, e por procurar maior credibilidade no mercado, muitas empresas tem procurado se cadastrar no Instituto Nacional de Metrologia, Normalização e Qualidade Industrial INMETRO.

Assim, com a Portaria n. .0158 , de 27 de junho de 2006, o INMETRO dispõe sobre o registro das empresas de recargas de extintores de incêndio:

Considerando a necessidade de avaliar a conformidade das empresas que realizam os serviços de inspeção técnica e manutenção de extintores de incêndio;

Considerando a necessidade de dar continuidade ao processo de melhoria, empreendido no Programa de Avaliação da Conformidade de Extintores de Incêndio, para que as empresas realizadoras de serviços de inspeção técnica e de manutenção dos extintores de incêndio atendam aos regulamentos técnicos do Inmetro;

Considerando a necessidade de melhor definir o processo de transição do mecanismo de certificação para o de declaração do fornecedor, adotado na avaliação da conformidade das Empresas de Inspeção Técnica e Manutenção de Extintores de Incêndio, resolve baixar as seguintes disposições: 
Art. 1 Aprovar o Regulamento de Avaliação da Conformidade para Registro de Empresa de Serviços de Inspeção Técnica e Manutenção de Extintores de Incêndio.

No art. $4^{\circ}$ da referida Portaria, está disposto sobre a necessidade das empresas de recarga de extintores de incêndio de conseguirem o Registro de Declaração de Conformidade do Fornecedor no Inmetro:

Art. 40 Determinar que, a partir de 1 ㅇ de julho de 2006, as empresas de inspeção técnica e manutenção de extintores de incêndio deverão obter o Registro de Declaração de Conformidade do Fornecedor no Inmetro, de acordo com o estabelecido no Regulamento ora aprovado.

Assim, existe a necessidade de todas as empresas terem este registro para poderem funcionar. No art. 5 estão sendo mostrados os critérios estabelecidos para tal:

Art. 5o Determinar que a transição do processo de Certificação do serviço de inspeção técnica e manutenção para o Registro de Declaração de Conformidade do Fornecedor dar-se-á de acordo com os prazos e critérios estabelecidos nos parágrafos e incisos abaixo explicitados.

$\S 1^{0}$ - Os contratos celebrados entre os Organismos de Certificação de Produtos e as empresas de inspeção e manutenção de extintores de incêndio obedecerão aos prazos seguintes:

I - os contratos novos, assinados entre a data de publicação desta Portaria e o dia 30 de junho de 2006, deverão ter vigência de, no máximo, 6 (seis) meses;

II - os contratos já celebrados, cujo vencimento ocorra no período entre a publicação desta Portaria e o dia 30 de junho de 2006, não deverão ser renovados por um período superior a 6 (seis) meses;
III - os contratos já celebrados, cujo vencimento ocorra entre $1^{\circ}$ de julho e 31 de outubro de 2006, não deverão ser renovados por período superior a 4 (quatro) meses.

$\S 2^{\circ}$ - A empresa de inspeção técnica e manutenção de extintores de incêndio, com contrato

ainda em vigor, que optar pelo acordo de rescisão contratual, poderá migrar para 0 novo mecanismo de Avaliação da Conformidade, sujeitando-se ao processo de verificação de acompanhamento, nos seguintes termos:

I - A empresa, cujo prazo de vencimento do contrato seja inferior a 12 (doze) meses, deverá pagar somente o valor referente a uma verificação de acompanhamento, não tendo qualquer ônus pecuniário,

referente ao registro, quando a migração for efetuada até 31 de dezembro de 2006;

II - A empresa, cujo prazo de vencimento do contrato seja superior a 12 (doze) meses e inferior a 30 (trinta) meses, deverá pagar o valor referente a 2 (duas) verificações de acompanhamento, previstas no Regulamento, não tendo qualquer ônus pecuniário, referente ao registro, quando a migração for efetuada até 31 de dezembro de 2006.

§ 3ำ - A concessão do Registro para empresa de inspeção técnica e manutenção de extintores de incêndio, com contrato ainda em vigor de autorização para uso da marca, ficará condicionada à apresentação de compromisso formal de rescisão contratual, firmado entre ela e o Organismo de Certificação de Produtos.

$\S 4^{0}$ - A empresa de inspeção técnica e manutenção de extintores de incêndio, com contrato ainda em vigor, deverá, até 1 de julho de 2006, articular-se com o seu Organismo de Certificação de Produtos para submeter seus serviços à certificação, com base no Regulamento Técnico de Qualidade - RTQ , aprovado pela Portaria Inmetro $\mathrm{n}^{\circ} \mathbf{8 0}$, de 3 de abril de 2006. 
Nota-se a necessidade desta concessão para que a empresa possa trabalhar normalmente. No art. $7^{\circ}$ está sendo mostrado que o Inmetro efetuará verificação das empresas registradas e no art. $8^{\circ}$ dispõe que a fiscalização destas empresas ficará por conta do Inmetro e das entidades de direito público conveniadas, em todo o território nacional:

Art. $7^{\circ} \bigcirc$ Inmetro deverá, a qualquer tempo, efetuar verificação de acompanhamento nas empresas Registradas no âmbito do Sistema Brasileiro de Avaliação da Conformidade, independente do processo de fiscalização.

Art. $8^{\circ}$ A fiscalização do cumprimento das disposições contidas nesta Portaria, em todo o território nacional, ficará a cargo do Inmetro e das entidades de direito público com ele conveniadas.

Assim, conforme pode ser notado acima, é necessário que exista um serviço extremamente controlado e que seja entregue ao destinatário com qualidade e excelência no funcionamento.

\section{CONCLUSÃO}

Ao concluir o presente estudo, evidenciase a importância, nos dias de hoje, do segmento de segurança do trabalho em contextos empresariais modernos. Pode-se perceber que a exposição a riscos no ambiente funcional repercute em danos à saúde e prejuízos nos resultados da empresa.

$\mathrm{Na}$ realidade, a exposição a riscos ocupacionais de qualquer natureza compromete 0 andamento das atividades laborais. Portanto, todo esforço deve ser realizado para que ambientes e postos de trabalho sejam adequados ao homem. Da descrição do comprometimento orgânico e psicológico, infere-se que o combate e a prevenção são os meios disponíveis para preservar a saúde dos profissionais. $O$ tratamento nem sempre é exeqüível, porém, a prevenção por planos de segurança devidamente calculados e personalizados ao ambiente a que se refere, concorrem à garantia de um melhor ambiente de trabalho.

Quanto a importância dos extintores de incêndio para as empresas, ficou nítido que esta proteção coletiva dentro dos ambientes empresariais fará com que a segurança aumente. Entretanto, é necessário oferecer treinamento para o seu uso correto. Outro ponto a ser observado é que os extintores devem estar carregados e conferidos, para que estejam adequados quando houver necessidade de seu uso. É necessário contratar empresas particulares de recarga de extintor de incêndio que realizam serviços e funções muito peculiares, já que, além de necessitarem de registro adequado, também lidam com a vida e morte de pessoas, pois um serviço mal feito ou com matéria prima em condições precárias pode levar alguém a morte. Reforça-se que as empresas devem ter um controle grande quanto ao serviço prestado, pois a responsabilidade civil dos funcionários sobre um serviço mal feito também é verificada, já que estes acabam praticando ato doloso ou culposo, na realização das tarefas relativas à temática abordada.

\section{REFERÊNCIAS}

ANVISA. A experiência do LACEN/AL no processo de implantação do sistema da qualidade. Disponível em: < http://www.anvisa.gov.br /reblas/oficinas/curso_distancia/lacen_al.ppt>. Acesso em: 29 abr. 2010.

ARAÚJO, G. M. Normas Regulamentadoras Comentadas. Rio de Janeiro: Edição GMA, 2005.

BRASIL. Lei ํㅜ 8.213. Dispõe sobre os Planos de Benefícios da Previdência Social e dá outras providências. 24 de julho de 1991.

BRASIL. Constituição Federal Edição atualizada. Brasília: Gráfica do Senado, 2004. 
BRASIL. Portaria no 3.214. Institui Normas Regulamentadoras, 1978.

BRASIL. Portaria o 3.237. Regulamenta regulamentou os Serviços Especializados em Engenharia de Segurança e Medicina do Trabalho (SESMT), 1972.

CARAVANTES, G. R.; CARAVANTES, B.; BJOUR, W. E. Administração e qualidade: a superação dos desafios. São Paulo: Makron, 1997.

DANNY. Disponível em: http://www.danny.com.br/danny.html>. Acesso em 20 abr. 2010.

DIAS, E. C. A Atenção à Saúde dos Trabalhadores no Setor Saúde no Brasil. Campinas: UNICAMP, 1996.

GLOBALTECH. Segurança do Trabalho. Porto Alegre: Globaltech, 2006. (CD-ROM).

INSTITUTO NACIONAL DE METROLOGIA, NORMALIZAÇÃO E QUALIDADE INDUSTRIALINMETRO. Disponível em: http://www.inmetro.gov.br/legislacao/rtac/pdf/RTA C001035.pdf>. Acesso em 20 abr. 2010.

SALEM, D. A. R.; SALEM, L. R. cidentes do trabalho. ão Paulo: Thompson IOB, 2005.

SALIBA, S. C. R. SALIBA, T. M. Legislação de Segurança, Acidente do Trabalho e Saúde do Trabalhador. São Paulo: Ltr, 2005. 